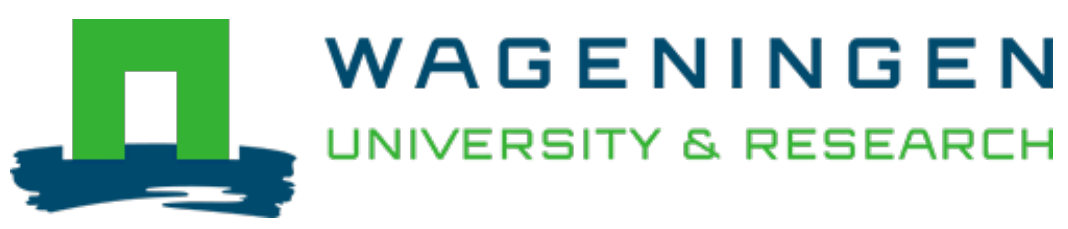

\title{
Stakeholder Dialogue as Agonistic Deliberation : Exploring the Role of Conflict and Self-Interest in Business-NGO Interaction
}

\author{
Business Ethics Quarterly \\ Brand, Teunis; Blok, Vincent; Verweij, Marcel \\ https://doi.org/10.1017/beq.2019.21
}

This article is made publicly available in the institutional repository of Wageningen University and Research, under the terms of article $25 \mathrm{fa}$ of the Dutch Copyright Act, also known as the Amendment Taverne. This has been done with explicit consent by the author.

Article 25 fa states that the author of a short scientific work funded either wholly or partially by Dutch public funds is entitled to make that work publicly available for no consideration following a reasonable period of time after the work was first published, provided that clear reference is made to the source of the first publication of the work.

This publication is distributed under The Association of Universities in the Netherlands (VSNU) 'Article $25 \mathrm{fa}$ implementation' project. In this project research outputs of researchers employed by Dutch Universities that comply with the legal requirements of Article $25 \mathrm{fa}$ of the Dutch Copyright Act are distributed online and free of cost or other barriers in institutional repositories. Research outputs are distributed six months after their first online publication in the original published version and with proper attribution to the source of the original publication.

You are permitted to download and use the publication for personal purposes. All rights remain with the author(s) and / or copyright owner(s) of this work. Any use of the publication or parts of it other than authorised under article $25 \mathrm{fa}$ of the Dutch Copyright act is prohibited. Wageningen University \& Research and the author(s) of this publication shall not be held responsible or liable for any damages resulting from your (re)use of this publication.

For questions regarding the public availability of this article please contact openscience.library@wur.nl 


\title{
Stakeholder Dialogue as Agonistic Deliberation: Exploring the Role of Conflict and Self-Interest in Business-NGO Interaction
}

\author{
Teunis Brand \\ Vincent Blok \\ Marcel Verweij \\ Wageningen University
}

\begin{abstract}
Many companies engage in dialogue with nongovernmental organizations (NGOs) about societal issues. The question is what a regulative ideal for such dialogues should be. In the literature on corporate social responsibility (CSR), the Habermasian notion of communicative action is often presented as a regulative ideal for stakeholder dialogue, implying that actors should aim at consensus and set strategic considerations aside. In this article, we argue that in many cases, communicative action is not a suitable regulative ideal for dialogue between companies and NGOs. We contend that there is often an adversarial element in the relation between companies and NGOs, and that an orientation towards consensus can be in tension with this adversarial relation. We develop an alternative approach to stakeholder dialogue called 'agonistic deliberation.' In this approach, conflict and strategic considerations play a legitimate and, up to a certain point, desirable role.
\end{abstract}

KEY WORDS: stakeholder dialogue, agonistic deliberation, consensus, conflict, self-interest, nongovernmental organizations

With pluralist market society spawning a never-ending series of social conflicts in fairly rapid succession, it differs from other types of socio-political arrangements in one important respect: it cannot pretend to establish any permanent order and harmony; all it can aspire to accomplish is to 'muddle through' from one conflict to the next.

-Albert O. Hirschman ${ }^{1}$

Tn the literature on corporate social responsibility (CSR), increasing attention is paid to the role that stakeholder dialogue plays in addressing and solving complex CSR-related issues. Dialogue is an indispensable aspect of the interaction between companies and nongovernmental organizations (NGOs), especially with regard to collaboration and partnership formation (Roloff 2008; Seitanidi and Crane 2009; Burchell and Cook 2013a; Selsky and Parker 2005; Van Tulder et al. 2016).

${ }^{1}$ Hirschman (1994, 213). 
The idea is that addressing complex societal issues - such as sustainability, human rights, or public health-requires dialogue and collaboration between multiple actors. The aim of this article is to get a better understanding of the norms that should govern stakeholder dialogues about complex societal issues. Generally, stakeholder dialogue is described as a practice by which companies shift from a one-way communication strategy towards a more responsive, two-way one with their stakeholders (Crane and Livesey 2003). Although there is often a broad set of stakeholders involved in such dialogues (companies, NGOs, governments, citizens, etc.), the focal point of our analysis is the interaction between companies and NGOs, specifically. ${ }^{2}$

Two elements stand out in the literature on stakeholder dialogue, namely, that participants should have a consensual orientation and that they should set strategic considerations aside (e.g., Baur and Palazzo 2011; Foster and Jonker 2005; GarcíaMarzá 2005; Unerman and Bennett 2004). We will argue that both elements are problematic when it comes to the interaction between companies and NGOs, especially when there are frictions between the commercial interests of companies and a societal issue. Our core arguments are that an orientation towards consensus is in tension with the function of NGOs to voice social criticism, and that the expectation to set aside strategic considerations is in tension with the idea of a competitive market in which companies are allowed to exhibit a certain partiality towards their own (commercial) interests. For these reasons, we believe that an alternative approach to dialogue is needed in which conflict and self-interest have a legitimate and, up to a certain point, desirable place.

Our analysis proceeds as follows. In the first section, we elaborate on the currently prominent conceptualization of stakeholder dialogue in the CSR literature and show that it strongly relies on Habermas's concept of communicative action. Following this, we discuss the problems of conceptualizing stakeholder dialogue in terms of communicative action. The last section provides an alternative way of conceptualizing stakeholder dialogue that we call agonistic deliberation, which incorporates the concept of agonism from the political philosophy of Chantal Mouffe (Mouffe 2005,1999 ) and builds on the concept of deliberative negotiation developed by Jane Mansbridge and others (Mansbridge et al. 2010; Mansbridge 2009; Warren and Mansbridge 2013). Our alternative stresses the importance of a struggle between companies and NGOs, and, at the same time, upholds mutual justification as a central deliberative norm.

\section{THE CURRENT CONCEPTUALIZATIONS OF STAKEHOLDER DIALOGUE}

What are the central characteristics of a good stakeholder dialogue as presented in the CSR literature? This question implies that we are not so much concerned with a descriptive view of stakeholder dialogue (what it actually looks like in practice),

\footnotetext{
${ }^{2}$ Strictly speaking, it is not companies and NGOs that engage in dialogue, but their employees or representatives. However, for reasons of convenience, we will 'non-strictly' speak as if companies and NGOs engage in dialogue.
} 
but with a normative view or an ideal. ${ }^{3}$ The ideal indicates where companies and stakeholders should be aiming in their communication with one another. Although we recognize that there is not one homogeneous view of stakeholder dialogue, we identify what seems to be the dominant normative view. After discussing the literature on stakeholder dialogue, we show how this view relates to the concepts of communicative and strategic action.

Before turning to the characteristics of the ideal stakeholder dialogue in the literature on CSR, we want to clarify what we mean by 'stakeholder dialogue' in general and what kind of stakeholder dialogues we focus on in this article. We understand stakeholder dialogue broadly as the two-way communication between companies and their stakeholders (Crane and Livesey 2003). More specifically, to count as stakeholder dialogue, it should be an organized or planned event in which participants deliberately engage and should stand apart from regular day-to-day communicative interaction. Furthermore, it should be a dialogue that concerns policies and activities at an organizational level. Although the topics in such dialogues and the participating stakeholders can both be widely diverging, we narrowed down for a specific focus. First, with regard to topics, our focus is on the way in which the activities of companies affect societal values. Examples of such values are public health, human rights, and sustainability. Second, with regard to participants, the analysis in this article is restricted to interaction between companies and NGOs. The choice for NGOs is motivated by the consideration that these organizations typically represent and promote societal values (Baur and Palazzo 2011; Martens 2002), and because they play an increasingly important role in CSR (Arenas, Lozano, and Albareda 2009).

\section{Characteristics of the Ideal Stakeholder Dialogue in the CSR Literature}

In the CSR literature, the ideal stakeholder dialogue is described as a dialogue in which the participants have a consensual attitude in regards to building a shared view about a societal issue (e.g., Baur and Palazzo 2011; Foster and Jonker 2005; Golob and Podnar 2014; Kaptein and Van Tulder 2003). Furthermore, commercial interests have, ideally, no influence on the process and the outcome, because the dominance, or maybe even the presence, of strategic considerations distorts the process of building a shared understanding (e.g., Crane and Livesey 2003; Unerman and Bennett 2004). As Noland and Phillips (2010, 40) put it, in a communicative approach to dialogue, communication is "uncorrupted by

\footnotetext{
${ }^{3}$ We recognize that there is a lot of literature adopting an instrumental approach to stakeholder engagement and dialogue, which generally assesses the extent to which stakeholder relations contribute to firm performance (e.g., Jones 1995; Berman et al. 1999; Choi and Wang 2009). There are basically two reasons why we do not discuss this approach in our article. First and foremost, our concern is with approaches that present a distinctively normative perspective on stakeholder dialogue. An instrumental approach to stakeholder engagement and dialogue cannot answer the question of what kind of norms and ideals should guide the interaction between companies and NGOs. Whether and how stakeholder dialogue affects firm performance is not our main interest (although it is relevant to have knowledge about this relation). Second, studies in this field often focus only on whether stakeholders interact or not, but not how they interact, while we are interested mainly in the latter.
} 
power differences and strategic motivations" with the aim of "agreement for the sake of agreement." When we refer to strategic considerations, we mean to refer to considerations that have to do with private interests as opposed to public interests. For example, having a good reputation is a private interest of a company or an NGO, but not a public interest. Contrariwise, the availability of healthy food is a public interest, namely, an interest of us all (although it is also in each person's private interest).

One of the central characteristics of the ideal dialogue as sketched out in the literature is that it aims to achieve consensus among participants. Although several authors make explicit use of this concept (Patzer, Voegtlin, and Scherer 2018; Golob and Podnar 2014; García-Marzá 2005; Foster and Jonker 2005), it is often not clear what they exactly mean by it. Other authors do not explicitly use the concept consensus, but emphasize that dialogue should lead to a "shared understanding' between stakeholders, which seems to imply some form of consensus (Johnson-Cramer, Berman, and Post 2003). Many authors make use of Habermas's theory of communicative action and his theory of deliberative democracy in which the importance of finding consensus is also emphasized (Roloff 2008; Scherer and Palazzo 2007; Palazzo and Scherer 2006; Foster and Jonker 2005; van Huijstee and Glasbergen 2008; Unerman and Bennett 2004). We find that the importance of finding consensus within stakeholder dialogue is often assumed, but receives little explicit attention.

Since we want to address the question of whether a consensus orientation is desirable in stakeholder dialogues between companies and NGOs, it is important to be clear on how we understand consensus. As we see it, a consensus is an agreement in the sense that actors hold the same belief about something (whether initially or as a result of dialogue) and know that others have the same belief. We agree with Habermas that a genuine consensus is based on reasons and is not the result of coercion (Habermas 1996, 1990). Now, of course, people can agree and disagree about a lot of different things. A useful distinction can be made between (dis)agreements concerning facts, values, and actions (Rescher 1993). ${ }_{4}^{4}$ For example, a person can hold the following beliefs: that sugar intake is the main cause of obesity, that public health is a prime value, and that food companies should reduce sugar levels in drinks. The first is a factual claim, the second relates to values, and the third relates to action. When engaging in a discussion, agreement and disagreement can appear at different levels. It could be that there is consensus about what to do, without there being consensus about the other levels. Hence, there are stronger and weaker forms of consensus. For example, there is a strong consensus between a food company and an NGO when they both adopt public health as a core value, have the same beliefs about the causes of obesity, and also share beliefs about how obesity should be addressed. Yet it is possible that, though they reach consensus about how obesity should be addressed, they do not have the same beliefs regarding the causes

\footnotetext{
${ }^{4}$ Taste (or subjective preference) is a fourth element where people can (dis)agree. However, it does not make sense to convince others of a certain taste, unless one of the other elements is also at play.
} 
of obesity nor have they adopted the same values. This would be a weak consensus (by which we do not mean to imply that such a consensus is necessarily unstable). ${ }^{5}$ Yet it is important to notice that, since it is a consensus about action, both parties genuinely, and on the basis of reasons, believe that what they agree on is the right thing to do.

A consensus should be distinguished from a compromise. A compromise is an agreement that reflects a "settlement of differences by mutual concessions" (Benjamin 1990, 5). To give an example, suppose that an NGO requests a company to stop child marketing, while the company wants to continue child marketing. After ample discussion, they agree to abandon child marketing on a limited set of unhealthy products, even though the NGO would prefer the company abandon child marketing altogether. Although they mutually agree to work out this course of action, it is not a consensus, because both had to give in, to some extent, on the course of action they initially preferred, and because at least one of the participants is not internally convinced, on the basis of reason, that this is the right thing to do. ${ }^{6}$

How can consensus be achieved? What does it require from participants? In the literature, different criteria for good stakeholder dialogue are discussed. Although not all authors explicitly mention consensus as the desired outcome, the following criteria that could enhance the achievement of consensus are mentioned in the literature. In the first place, participants in a dialogue should be willing to change their minds (Burchell and Cook 2006; Crane and Livesey 2003). Furthermore, the communication should be symmetrical, in the sense that the different parties have equal opportunities to present their points of view (Crane and Livesey 2003; Foster and Jonker 2005). In order to make sure that a dialogue does not favor a particular view, it is important that a diversity of voices be heard (Payne and Calton 2002). Participants should also never be forced to adopt a certain position, but they should be allowed to develop their own positions on the basis of sound arguments (Roloff 2008; Unerman and Bennett 2004). The problem is that even if all these requirements are fulfilled, consensus - whether in its stronger or weaker form - will not always be achieved. The difficulty to achieve consensus, especially under conditions of pluralism, is often acknowledged (Baur and Palazzo 2011; Mena and Palazzo 2012). At the same time, it is maintained that an orientation towards consensus is crucial. For example, Mena and Palazzo (2012) consider a consensual orientation as one of the criteria for evaluating the input legitimacy of multi-stakeholder initiatives. Similarly, Baur and Palazzo hold that even though it may be difficult to achieve consensus as the final outcome, NGOs and companies must at least show "the principle willingness to achieve a shared position" (Baur and Palazzo 2011, 693, our emphasis). So, even though it is recognized in the literature that consensus will often not be achieved in practice, it is presented as something to strive for.

\footnotetext{
${ }^{5}$ There are also other weaker and stronger forms of consensus. For example, it could be that people have the same beliefs, but for different reasons. This is what Rawls (1987) calls an 'overlapping consensus.' This form of consensus can also be called 'weaker' compared to a consensus in which people have the same reasons for having a belief.

${ }^{6}$ It may be noted that agreement is used for both consensus and compromise. In what follows in the article, we will use agreement only when it could include both.
} 
The ideal stakeholder dialogue, with its focus on consensus, is often contrasted with a dialogue in which participants are merely trying to defend and pursue their own interests. Van Huijstee and Glasbergen $(2008,300)$ refer to this as the strategic management perspective of dialogue in which "companies are motivated to engage with stakeholders to manage risk . . . and to gain competitive advantage." When dialogue is used for merely strategic purposes, it can become a form of manipulation or propaganda (Bendell 2003; Golob and Podnar 2014). It is called an 'instrumental dialogue' because it is merely seen as a means to achieve the private ends of an individual or organization (Crane and Livesey 2003). In that case, the dialogue is not really open for different views, but is "centred on communicating self-interest and aligning the other's interest to one's own" (Crane and Livesey 2003, 47). We are, thus, presented with a dichotomy. At one end of the spectrum lies the ideal dialogue in which participants aim at a rationally motivated consensus. At the other end lies a dialogue in which actors treat each other strategically.

\section{Stakeholder Dialogue and Habermas's Philosophy}

Many readers will recognize in the CSR literature about stakeholder dialogue an indebtedness to the philosophy of Jürgen Habermas, both in content and in terminology. Indeed, many business ethics scholars who study the interaction between companies and its stakeholders make use of Habermas's work. For example, from the perspective of stakeholder theory, Phillips (1997) has argued that Habermas's discourse ethics provides an appropriate procedure for determining the obligations that companies have towards their stakeholders. Other approaches within business ethics use the philosophy of Habermas as well to defend the importance of deliberation in the business context, appealing to his theory of discourse ethics (Gilbert and Rasche 2007; Rasche and Esser 2006; Reynolds and Yuthas 2008; Unerman and Bennett 2004; Zakhem 2008) or to his theory of deliberative democracy (Palazzo and Scherer 2006; Scherer and Palazzo 2007; Scherer et al. 2016). Despite the difference between these approaches, they all hold that CSR activities should be validated within processes of deliberation with stakeholders and society.

A fundamental distinction in Habermas's work, underlying both his discourse ethics and his theory of deliberative democracy, is the distinction between communicative and strategic action. A brief discussion of the distinction between communicative and strategic action will increase our understanding of the conceptualization of stakeholder dialogue in the CSR literature. Habermas's conception of communicative rationality is most extensively worked out in The Theory of Communicative Action (Habermas 1985, 1987). He speaks of communicative action "when actors are prepared to harmonize their plans of action through internal means, committing themselves to pursuing their goals only on the condition of an agreement ... about definitions of the situation and prospective outcomes" (Habermas 1990, 134). Crucial in this definition is that actors pursue their goals on the basis of a shared definition of the situation. That means that actors, when confronted with a certain action problem, communicatively arrive at a consensus about what is at stake and what should be done about it. In communicative action, an action problem will be 
dealt with on the basis of this consensus. When Habermas writes that actors are prepared to harmonize their plans of action through internal means, he means that actors convince each other about the interpretation of the situation on the basis of arguments in a way that each can freely accept: "In discourse what is called the force of the better argument is wholly unforced. Here convictions change internally via a process of rationally motivated attitude change" (Habermas 1990, 160). Communicative action, therefore, is a form of communication that aims to achieve a consensus based on rational argumentation.

Habermas contrasts communicative action with strategic action, by which actors influence each other through external means:

If the actors are interested solely in the success, i.e., the consequences or outcomes of their actions, they will try to reach their objectives by influencing their opponent's definition of the situation, and thus his decisions or motives, through external means by using weapons or goods, threats or enticements. Such actors treat each other strategically (Habermas 1990, 133).

According to Habermas, the use of external means connects strategic action to coercion (cf. Johnson 1991). In that way, it is the opposite of communicative action. A person who changes his action plan in response to a threat or a promise might not be internally convinced of the alternative, but is forced (however weak the force may be) to adopt it. Actors that act strategically try to influence one another, in order to achieve their own interests.

Despite the strong distinction that Habermas draws between communicative and strategic action, he does recognize that strategic action, as well as mixed forms of strategic action and communicative action, might legitimately appear in the real world. Firstly, Habermas recognizes that interaction in a market economy is largely (although not entirely) based on strategic action, which he does not consider to be problematic as such (Habermas 1996). Hence, his conception of communicative action is not meant to replace all forms of strategic action. Secondly, his model of deliberative democracy also includes the balancing of interests and compromise formation (Habermas 1998). At the same time, Habermas maintains that the procedures for a fair compromise must presuppose the discourse principle, which "is supposed to secure an uncoerced consensus" (Habermas 1996, 166). The normative force of an orientation towards consensus, therefore, plays a crucial role throughout Habermas's philosophy (Markell 1997). ${ }^{7}$

The distinction between communicative and strategic action resembles the distinction between the ideal dialogue and the instrumental dialogue, which we identified in the CSR literature. These two types of stakeholder dialogue are presented as the

\footnotetext{
${ }^{7}$ This article is not meant as an interpretation of Habermas, nor is it a critique of his philosophy. That would require a much different approach, delving much deeper into his work. The distinction between communicative action and strategic action is used heuristically, to better understand the CSR literature about stakeholder dialogue. Our main interest is to reflect on whether a consensual orientation is desirable or not in the interaction between companies and NGOs, and not whether the view we develop conflicts with or could be brought in alignment with Habermas's philosophy.
} 
two ends of a spectrum, and they define each other negatively. For example, Patzer et al. $(2018,342)$ hold that "a main precondition is that stakeholder engagement should be based on a communicative rationale and the main objective should be to reach consensus, rather than fulfill strategic intentions." Likewise, Foster and Jonker (2005, 54-55) claim that Habermas's concept of communicative action "is the only sort of action that can be said to allow a constructive dialogue and reasonable action," while strategic action is about "egoistic success." In a strategic or an instrumental dialogue, participants do not seek agreement as something worthy in itself, but try to influence others to advance their own ends. In this opposition, strategic considerations or considerations of self-interest have a rather negative connotation. A dialogue in which they play an important role is characterized as corrupted or distorted. Hence, our conclusion that communicative action functions (whether explicitly or implicitly) as a regulative ideal for stakeholder dialogue. In other words: for many authors in this field, communicative action provides the standards in terms of which the quality of a stakeholder dialogue should be assessed.

\section{PROBLEMS OF THE CURRENT CONCEPTUALIZATION OF STAKEHOLDER DIALOGUE}

We want to raise the question of whether communicative action (especially the orientation towards consensus) is a proper ideal for stakeholder dialogue between companies and NGOs. Do we actually want those actors to aim at consensus? Why or why not? And can we expect them to ignore strategic considerations? This section outlines several problems with conceptualizing stakeholder dialogue in terms of communicative action. First, we recall some criticism that has been brought forward in the literature. This criticism mainly focuses on the fact that communicative action cannot be achieved in practice, because its standards are too high. Second, we outline what we consider to be a more fundamental problem, namely, that a focus on consensus can be problematic also as a regulative ideal for stakeholder dialogue between companies and NGOs.

\section{Criticism on Conceptualizing Stakeholder Dialogue in Terms of Communicative Action}

The ideal of stakeholder dialogue based on communicative action has been criticized in several articles, mainly by highlighting that communicative action cannot be realized in practice. Høvring, Andersen, and Nielsen $(2018,643)$ argue that the complexity of the practice of stakeholder dialogue receives too little attention and, thus, that there is "an overall tension between an idealization of CSR dialogue versus a realistic execution." They also argue that in the practice of stakeholder dialogue, there remains a tension between the commercial and the societal responsibilities of a company. Burchell and Cook (2013a) show that the key motivations for companies to engage in dialogue with NGOs are reputation management and maintenance of their license to operate. These motives concern the private interests of the company instead of a public interest. Moreover, they note that some companies use dialogue with NGOs to silence criticism, while continuing 
business as usual. This is a form of co-optation, which means that an actor is able to "bring the interests of a challenging group into alignment with its own goals" (Trumpy 2008, 480; see also Baur and Schmitz 2012). Another risk occurs when participants are pushed to reach a consensus: the risk of creating a false consensus (van de Kerkhof 2006). In that case, a consensus-oriented dialogue may turn out to serve the interests of the most powerful actors (Brown and Dillard 2013; Dawkins 2015). Moog et al. (2015) show in their case study of the Forest Stewardship Council that it became dominated by commercial concerns, regardless of the fact that the governance structure of this multi-stakeholder initiative was explicitly designed to include different voices. They argue that this relates directly to the limited resources NGOs have compared to multinational corporations.

It is questionable whether this criticism necessitates the rejection of communicative action as a regulative ideal for stakeholder dialogue. The fact that an ideal is far from realized in practice does not, as such, provide a good reason to reject it. Many, if not all, adherents of consensus-oriented stakeholder dialogue recognize that the ideal is often not achieved in real life. One could say that an ideal is always counterfactual: it is the very function of an ideal to be aspired to, even though its complete realization may not be possible. Therefore, communicative action could probably function for stakeholder dialogue as a regulative ideal "that provide[s] standards at which to aim, not criteria that if not met disallow the process" (Warren and Mansbridge 2013, 90). Some authors, however, have also argued that a consensus-oriented dialogue might not be a proper ideal. Høvring et al. (2018) have argued that conflict and dissensus can also be a source for social change. Blok (2014a) has noted that the emphasis on harmony and alignment in the literature on partnership formation neglects the fact that there can be fundamental differences (in views and interests) between stakeholders (see also Blok 2018, 2014b). Sabadoz and Singer argue that the business context, as such, is hostile to consensual deliberation, because "the purpose of the market is precisely to orient behavior with minimal concern for moral consensus" $(2017,195){ }^{8}$ This criticism on a consensus orientation in stakeholder dialogue does not only apply to business-NGO relations, but also to other stakeholder relations. We want to address the question of why, specifically for companies and NGOs, consensus can be a problematic regulative ideal.

\section{The Market as Adversarial and Nonideal Institution}

Companies operate within the institutional context of the market. At its core, this means that the exchange of goods and services is mediated by prices, which are established through a process of supply and demand. The virtue of the price

\footnotetext{
${ }^{8}$ Sabadox and Singer (2017) discuss the general question of whether markets are an appropriate context for (consensual) deliberation (and their answer is negative). Although we agree with much of their argument, our approach is different. Our question is: Given the fact that companies and NGOs do engage in dialogue, what norms should and should not guide their communicative interaction? In a way, this article picks up their suggestion that different contexts might require different deliberative standards (Sabadoz and Singer 2017, 201-2).
} 
mechanism is that it helps to bring supply and demand together in an efficient way, at least compared to a system of central planning. Instead of carrying out specific orders, demand and supply are brought together by letting companies compete for the favor of customers. The element of competition is characteristic for what Heath calls adversarial institutions, which he defines as institutions "whose social function is discharged, not by having participating individuals intend the desired outcome, but . . . letting the desired outcome arise as a (typically unintended) consequence of the agonistic interaction that results" (Heath 2019, 350). The idea is that, while the purpose of markets is to realize overall efficiency and market-clearing prices, corporate managers do not directly intend that goal, but indirectly contribute to it by aiming at the proper functioning of their particular company, often understood in terms of the pursuit of profit. Heath notes that seeing the market as an adversarial institution implies that companies are allowed to exhibit a certain partiality, which permits the pursuit of profit. This permission is indirectly justified by the overall beneficial effects that the pursuit of profit and competition have on the functioning of the price mechanism.

As an adversarial institution, the market is also a nonideal institution. Companies are allowed to exhibit a certain partiality through the pursuit of profit in order to obtain the overall benefits of competition. This permission implies that, to a certain degree, companies are allowed to impose harm on others: lowering one's prices might harm competitors, and dismissing employees in order to secure the survival of a company is also in tension with some strong moral intuitions (Heath 2019; cf. Applbaum 1999). It is important to acknowledge that there is a risk in the permission to pursue profits: companies may take this as license for the unconstrained pursuit of their commercial interests at the expense of everything else. If only a few actors in the market think and act like this, the very element of competition might create a perverse incentive for other companies to do the same (given that firms can reap financial benefits from acting this way, at least in the short term).

The permission to pursue profits does not imply that companies should maximize profits. Companies can have-and probably should have-very different reasons for doing what they do, and one of their main motivations might be to contribute to society by delivering high quality products (although they will need to do this in a profitable way). The point is that the market morality at least permits the pursuit of profit, and the idea of markets as adversarial institutions aims to justify this permission. Furthermore, the permission to pursue profits does not exempts companies from their social responsibilities. Although most business ethicists accept that the pursuit of profit is legitimate, they maintain that companies have social responsibilities besides their economic objectives, whether these are grounded in their responsibilities towards stakeholders (e.g., Freeman et al. 2010), in their duty to refrain from profiting off of market failures (Heath 2014), or in the political nature of corporations (e.g., Scherer and Palazzo 2007). Yet all these theories have to account for the fact that the social responsibility of companies is limited due to the competitive nature of the market and the permission to pursue profits (Dubbink 2004). 
As a nonideal institution, the market exhibits some structural problems, for which it stands in need of correction. A common correction is government policies that countervail market failures and promote competition. Self-regulation and CSR can also contribute to correcting market failures and the neglect of public values (cf. Norman 2011). A third form of correction comes from civil society: citizens and NGOs that try to hold companies accountable for what they are doing, or work together with companies in order to improve their performance in relation to societal issues (cf. Crouch 2011). In order to shed more light on the role of NGOs, we now turn to a short discussion of their societal role.

\section{Advocacy NGOs as Response to a Nonideal World}

Advocacy NGOs (also called watchdog or social movement NGOs) are nonprofit organizations that promote a specific societal value (Martens 2002; see also Baur and Palazzo 2011; Baur and Schmitz 2012; Yaziji and Doh 2009). ${ }^{9}$ We conceive of societal values as those values that are regarded by a substantial part of society as objects of worth and regard, for which they need the attention of different societal actors. ${ }^{10}$ If there were no societal problems that threatened those values, or if companies and other societal actors were to already recognize and address these problems, many NGOs would probably not exist. These organizations are, so to say, a response to the fact that we live in a nonideal world. By implication, they do not accept the status quo, but aim to change practices that relate to their mission and engage in social criticism. ${ }^{11}$ Of course, that NGOs are supposed to defend and promote societal values does not mean that everyone agrees with their mission and actions: what counts as societally valuable can always be contested. Furthermore, NGOs can also be used as a vehicle for group interests. However, without saying that NGOs always genuinely serve the public interest, they are, at least, the type of organization that we can expect to do so. They have (or should have) a social purpose, and people support or become a member of those organizations on the basis of their social purpose (Hussain and Moriarty 2016). Whether they serve this social purpose properly can always be subjected to critical scrutiny.

The strategies that NGOs adopt to pursue their mission can be very different. An important distinction has been made between radical and moderate, or reformative activist, groups (e.g., den Hond and de Bakker 2007; Mena and Waeger 2014). Reformative groups are understood as more willing to cooperate with

\footnotetext{
${ }^{9}$ Our analysis is restricted to advocacy NGOs, in contrast to service NGOs that deliver certain goods or services to their members. See Yaziji and Doh (2009) for difference between these types.

${ }^{10}$ By talking about a 'substantial part of society,' we want to avoid the pitfall that only those values about which there is consensus, or which are held at least by a majority of society, are regarded as societal values. In our definition, societal values can be contested and need not be held by a majority.

${ }^{11}$ There might be NGOs that actually try to retain the status quo, but only if the status quo is challenged by some negative force. In that case, they still want to change something, namely, to stop the negative trend.
} 
companies as compared to radical groups. Yet, despite their differences in tactics, the goal of both types of NGOs is similar, namely, to change current practices to protect the values they defend. Specifically, in addressing corporate behavior, their goal is to improve "firm practices with respect to social, environmental, or ethical CR [corporate responsibility] issues" (Mena and Waeger 2014, 1096).

\section{Why Dialogue between Companies and NGOs Requires Nonideal Normative Principles}

Although this short exercise about the market as a nonideal institution and the societal function of NGOs may be somewhat oversimplified, it aims to make clear that there is an adversarial element in the relation between companies and NGOs. Companies operate within the fallible institution of the competitive market, which requires correction and social criticism. NGOs play an important corrective role and voice social criticism and, therefore, it does not come as a surprise that many CSR scholars insist that companies should engage in dialogue with NGOs. We argue, however, that the insistence on the importance of consensus in such dialogues is problematic, and that nonideal normative principles are necessary to guide the interaction between companies and NGOs. We contend that an orientation towards consensus as regulative ideal can be problematic for two reasons. First, an orientation towards consensus requires a certain impartiality, namely, the ability to set aside one's particular interests in relation to a societal issue. This can be very difficult for companies, especially when their strategic interests are in tension with addressing a societal problem. Put differently, an orientation towards consensus can be in tension with the permission that companies have (and which is constitutive for the functioning of the market) to pursue the particular interests of their company. Second, consensus implies the convergence of beliefs, as we noted before. In certain cases, this can be undesirable given the role that NGOs have as agents of social criticism. This is so mainly because their identity might be dependent on specific views about societal values, but also because they are, in many cases, financially supported by donors and members because of their activism and critical attitude. Hence, an orientation towards consensus from their side can be conflicting with their role of challenging companies to pay more attention to certain societal values.

That a consensus orientation can be problematic as regulative ideal, indicates that it is not necessarily so. We contend that problems with a consensus orientation arise especially when a convergence in beliefs jeopardizes the core activities or views of one or more of the parties in a dialogue. For companies, this situation crops up when their production processes or products themselves contribute to societal problems or are the subject of societal debate. For example, there are tensions between the activities of beverage companies and the public's health, because the (excessive) consumption of sugar-sweetened beverages contributes to problems like obesity (cf. Iivonen 2018). The same holds for transport companies and the emission of fossil fuels. This does not mean that such companies do not have to change their processes of products. Yet even though they might recognize the problematic relation of their activities to a social problem, and even though they might be willing to change, 
they cannot simply set their current commercial interests aside, nor is it likely that they are always able to meet the ideals of NGOs. Striving after consensus with a public health or environmental NGO threatens the identity of such companies more directly compared to companies whose activities are contingently related to a societal problem.

For NGOs, the problems of a consensus orientation are similar. For them, aiming at consensus in a dialogue with companies whose activities are strongly at odds with their mission constitutes a threat to their identity. Of course, it could be that also in these cases, a consensus arises at certain points. But arguing that NGOs should always strive after it, or marking a consensual orientation as criterion for their legitimacy, is a different thing (cf. Baur and Palazzo 2011). Contrariwise, we suggest that a certain cautiousness to achieve consensus with companies (whose interests and activities are in conflict with their mission) is a more appropriate mark for their legitimacy. Hence, we argue that in such cases, it is better to give up the regulative ideal of consensus and instead adopt nonideal normative principles.

\section{AGONISTIC DELIBERATION: INCORPORATING SELF-INTEREST AND CONFLICT WITHIN STAKEHOLDER DIALOGUE}

Based on our analysis, we propose an alternative view of stakeholder dialogue. This alternative is not meant to replace, but to complement other forms of stakeholder dialogue. We call our alternative agonistic deliberation, because the dialogue between companies and NGOs will often be a form of deliberation between adversaries. In what follows, we first discuss the sources of inspiration for our approach, and in what way our approach differs from these sources. After that, we describe what agonistic deliberation entails.

\section{Sources of Inspiration: Agonistic Pluralism and Deliberative Negotiation}

Our approach to stakeholder dialogue is inspired by two main sources: (1) Chantal Mouffe's agonistic pluralism and (2) the idea of deliberative negotiation developed by Jane Mansbridge (among others). From Mouffe (1999, 2005) we borrow the concept of agonism, which we translate to the relation between companies and NGOs. The work of Mansbridge is used as inspiration for how to incorporate issues of conflict and self-interest within deliberation (Mansbridge 2009; Mansbridge et al. 2010; Warren and Mansbridge 2013). In what follows, we shortly describe those two approaches and which elements we adopt for our own conceptualization of stakeholder dialogue.

Mouffe's approach to political philosophy_agonistic pluralism-criticizes the theory of deliberative democracy, with its emphasis on seeking rational consensus. According to Mouffe, politics always has an inherently conflictual, or antagonistic, dimension. In this view, the aim of democracy is not to eradicate conflict (since that would be impossible), but to domesticate it (Mouffe 1999). Mouffe explains how this domestication of conflict could work by drawing a distinction between an antagonist and an adversary. The first is an enemy: someone who is to be destroyed. 
The second is an opponent, "somebody whose ideas we combat but whose right to defend those ideas we do not put in question" (Mouffe 2000a, 102). The essence of agonistic pluralism consists of accepting that there are unbridgeable differences between ideologies (pluralism) and the conception of politics as a struggle between adversaries (agonism).

This approach to political philosophy has been used by several authors to understand the relation between companies and their stakeholders. For example, by using Mouffe's philosophy, Burchell and Cook "seek to re-emphasise the importance of conflict and challenge within analysis of CSR and stakeholder dialogue" (2013b, 742). They argue that the relations between companies and NGOs are best interpreted as agonistic: there is a struggle between those actors about the meaning and content of the social responsibilities of companies. Another approach to stakeholder engagement based on Mouffe's agonistic pluralism was developed by Dawkins (2015). In his view, the problem with most approaches to stakeholder engagement is that they fail to pay sufficient attention to the (often unequal) power relations between stakeholders. He argues that there is a "clear need for countervailing voice" $(2015,11)$ to counter (corporate) hegemony. The aim of his agonistic approach to stakeholder engagement is to make a 'fair fight' between stakeholders possible, where dissensus and conflict are not seen as something negative.

Agonistic pluralism provides a promising alternative to the idealized conception of consensual deliberation, by seriously taking into account conflict and issues of power. However, we think that this approach suffers from a significant problem, which relates to the fact that Mouffe sees the agonistic struggle between adversaries as a struggle for hegemonic power (Mouffe 2005; see also Rummens 2009). According to Dawkins (2015) and Burchell and Cook (2013b), the struggle between companies and their stakeholders can also be interpreted as a hegemonic power struggle. Although this can be true from an empirical point of view, it would be very problematic from a normative point of view. In our view, striving for hegemonic power is at odds with the very idea of agonism. Agonism implies respect for one's opponent and for the rules of the game. This conflicts with seeking hegemony, which means that one view or group dominates over others (cf. Knops 2007; Erman 2009; Rummens 2009). Hence, we would argue that adopting an agonistic attitude means that actors abstain from seeking hegemonic power. To illustrate this point, consider a criminal trial procedure. This is an institution in which a prosecutor and defense lawyer are adversaries: they represent and defend opposing views and interests (see also Applbaum 1999; Heath 2019). However, if one of the parties would seek and achieve hegemonic control over the other, the very institution-which is meant to represent both sides-would be dissolved. This also holds in the context of business-NGO interactions: companies and NGOs both fulfill valuable roles, and it is undesirable that one group would ever come to dominate the other. So, even though we adopt the idea of agonism from Mouffe's philosophy, this should rather be interpreted as a rejection of the legitimacy of a struggle for hegemony between companies and NGOs.

The work of Mansbridge-our second source of inspiration-is located within deliberative democracy. In her work, she has analyzed how conflict and self-interest 
can have a legitimate place within deliberation (Mansbridge et al. 2010). Many deliberative democrats draw, in one way or another, on the distinction between communicative and strategic action. The first is connected with arguing, consensus, and the public good; the second with bargaining, conflict, and private interests (Elster 2000). By drawing on this distinction and, of course, by emphasizing that deliberative democracy should rely on the first part, Mansbridge argues that deliberative democrats discard the legitimacy of conflicts over self-interest within deliberation (Mansbridge 2006). As an alternative to this dichotomy, she and others have developed a typology of agreement seeking procedures, where agreement includes both consensus and compromise (Warren and Mansbridge 2013). In between pure deliberation and pure bargaining, a place is given to 'deliberative negotiation.' Deliberative negotiation is a process in which actors "make and respond to claims, arguments, and proposals with the aim of reaching mutually acceptable binding decisions ... based on processes of mutual justification, respect, and reciprocal fairness" (Warren and Mansbridge 2013, 92). Deliberative negotiation differs from pure deliberation in at least the following ways: it allows for (conflicts of) self-interest as legitimate part of the process, and it accepts compromise (besides consensus) as a legitimate outcome. Other goals, like clarifying conflict and increasing mutual understanding, also fall within the scope of deliberative negotiation.

We think that the notion of deliberative negotiation can be fruitfully applied to business-NGO interaction. Although the meaning of agonistic deliberation is quite close to this notion, we choose the adjective agonistic in order to stress the adversarial element in the relation between companies and NGOs. Furthermore, we wanted to avoid the word negotiation because it suggests that a conflict between parties can be reduced to differences in private interests. In the case of conflict between companies and NGOs about societal issues — characterized by their public nature - this would be problematic, even though it affects private interests. We define agonistic deliberation as an approach to dialogue between adversarial stakeholders in which enduring conflict in views and interests is legitimate and to some extent desirable, yet in which participants are willing to mutually justify and accommodate their views on how to address a societal issue. On the one hand, this approach recognizes the differences between actors and the possibility of enduring conflict. On the other hand, it retains a certain ideal as to how participants should treat each other. By noting that agonistic deliberation is an approach to dialogue between adversarial stakeholders, we leave room for other types of dialogue. As we noted before, this adversarial element is especially present when there are strong tensions between the core activities of companies and the missions of NGOs. Our approach to dialogue is specifically tied to those situations in which there is such an adversarial element in the relation between stakeholders.

\section{Conflict in Agonistic Deliberation}

A distinguishing element of agonistic deliberation is that it recognizes the possibility of enduring conflict between companies and NGOs. Conflict and contestation between those actors can be necessary and desirable for at least three reasons. 
First, it plays a role in creating awareness of societal problems, mobilizing support for change, and urging actors to take responsibility. The need of partisanship and conflict for mobilization is strongly emphasized by Mouffe (e.g., 2005). In some cases, citizens may come to realize the urgency of a certain issue only after NGOs have publicly criticized a company's problematic activities. And companies may sometimes only resort to action after having been criticized in such a campaign. Second, conflict and contestation will be necessary because new situations will always create new problems and challenges that call for new responses. For this reason, agreements between companies and NGOs are likely to be tentative, and existing ways of addressing a problem might become out of date. Third, conflict might be necessary in order to fight power imbalances (Dawkins 2015). When companies use their power to defend their interests in a way that conflicts with public interests, it is the role of NGOs to make this visible and to contest this use of power. For that matter, we must recognize that NGOs can misuse their power, too. For example, when an NGO has achieved an influential position, it can be in their interest to retain the status quo, without really contributing to societal change. For that reason, it is also important to critically examine the activities of NGOs and hold them accountable for these activities. This critical role can be fulfilled by citizens and other NGOs.

NGOs have different means for creating awareness, calling for new responses, and fighting power imbalances. Campaigning, especially through the media, is the most well-known way to do so. The question might be raised as to whether dialogue is a proper venue for conflict. Why not campaign when there is conflict and only engage in dialogue when there is a possibility of consensus? Does it make sense to engage in dialogue when there is no prospect of consensus? We would like to turn this question around: Would it make sense to refrain from engaging in dialogue for the mere reason that actors are hesitant to aim at consensus? If that would be the case, companies will only deliberate with NGOs whose views are (potentially) close to theirs, with the risk that NGOs that criticize their activities will not be taken seriously. In addition, consensus, or something close to it, is not the only valuable outcome of dialogue. Dialogue is also relevant and important when there is and will remain a certain conflict: even without a prospect of consensus, dialogue might help to clarify the conflict, increase mutual respect, and create awareness a societal problem (Warren and Mansbridge 2013). Furthermore, as shown by empirical research, campaigning and engaging in dialogue are not mutually exclusive strategies. Burchell and Cook (2013a) report that NGOs sometimes engage in dialogue with the same companies whose activities they are campaigning against, even though these companies want them to stop their campaigns.

When companies and NGOs deliberate, the tensions between them will likely be persistent, since we can expect that both parties will continue to have different views about how societal issues should, ideally, be addressed. Parties will often have to accept that compromises are inevitable if they want to reach an agreement. As Mouffe notes, compromises "should be seen as temporary respites in an ongoing confrontation" (Mouffe 2000b, 16). In such agreements, the threat of exit is always present, both from the side of companies and NGOs (Sabadoz and Singer 2017; cf. Hirschman 1970). There is always a risk that one of the parties will withdraw from 
an cooperative agreement, if they consider their interests harmed or their views not taken into account. This happened, for example, with the Forest Stewardship Council, from which several NGOs withdrew (Moog, Spicer, and Böhm 2015). The purport of agonistic deliberation is to recognize this possibility, which is one of the reasons why we do not want to preclude the legitimacy of conflict within deliberation.

\section{Self-Interest in Agonistic Deliberation}

We have shown that authors who conceptualize a good stakeholder dialogue in terms of communicative action do not consider self-interest to have a legitimate place in it. Yet both companies and NGOs have certain interests that deeply influence their functioning. We contend that it would be better to explicitly put these interests on the table within a dialogue, especially when they are in tension with addressing a societal issue. The commercial interests of companies are related to their responsibilities towards owners, employees, suppliers, etc. These interests are a legitimate and essential part of business. Concealing them for the sake of reaching agreement with NGOs is not likely to result in stable agreements. Moreover, hiding self-interested motives behind well-sounding arguments could lead to (mutual) distrust.

Companies must also understand that it is in the interest of NGOs to retain a certain independence from companies. A reputation of independence is necessary for the identity of an NGO and its ability to raise funds. If an NGO is seen as making agreements too easily with companies, it risks losing its legitimacy in the eyes of the public. Consequently, in an agreement between companies and NGOs on how to address a societal issue, the interests of both parties in an agreement must be sufficiently taken into account. We, therefore, hold that self-interest has a legitimate place within stakeholder dialogue, because it is informative of and has influence on the positions of participants.

Clearly, self-interest is relevant as information within a dialogue (Mansbridge 2006). But, could it also count as justification for adopting a certain position? Is it sufficient to argue that we are against this proposal, because it does not match our interest? We hold that this is not sufficient for a justification of one's view. Still, there is a difference between companies and NGOs and the role that self-interest plays in determining their position. As we said before, the functioning of a competitive market relies on the permission to pursue self-interest within certain limits (Heath 2019 , 2007). In order to have the benefits of the competitive market, companies are allowed to adopt a certain partiality in their actions, namely, to pursue what is in the interest of their constituencies-whether those are only the shareholders or a broader (but still limited) set of stakeholders. Hence, it would be inconsistent to expect companies to adopt a completely impartial point of view in a dialogue about societal issues.

The case for NGOs is different. Because of the partiality that companies exhibit and the consequent risk that they take societal issues into account too infrequently, NGOs represent those societal issues in order to correct them. NGOs must be able to justify their activities with reference to the societal values they support, because supporting those values is their core function. Admittedly, NGOs also exhibit a kind 
of partiality, since they only defend a very particular subset of all relevant societal values. Yet that makes it even more important for them to justify why these particular values are important and require the attention of other societal actors. That does not mean that strategic considerations are irrelevant for NGOs. They have to raise money and gain public support in order to be able to carry out their mission. Still, because the core function of advocacy NGOs is to serve societal values, we can expect that their strategic considerations are instrumental to the societal goals they pursue. At the same time, there can be tensions between considerations that relate to raising money or gaining public support and their overall mission. For example, NGOs might have to focus on different topics than they would prefer to, because they failed to raise money for the topics they deemed most important. When this is the case, it might also influence their input within a dialogue. So, even though it remains crucial for NGOs to be able to justify their views and activities with reference to the societal values they support, we cannot simply declare it invalid if they make use of strategic considerations within a dialogue.

What to do, it might be asked, if there is a strong conflict between public interests and the private interests of an actor within deliberation? Should not public interests always trump private interests? Are private interests not, in the end, irrelevant when it comes to taking a normative position? We do not think so. Of course, there are clear cases of such conflict where public interests should prevail. Consider the interests that a food company might have in hiding information about the negative health effects of certain additives. Their interests provide them with no (sufficient) reason to hide the information. But the case already becomes more complicated when we think about unhealthy products that make up a significant part of the portfolio of some food companies. Should they abandon such products for the sake of public health? By giving this example we do not mean to say that such companies should not change anything. We only seek to make the point that we cannot simply say that public interests always trump private interests. Conflicts between these two can be genuine ethical conflicts, for which they should be a topic of discussion within deliberation.

\section{Compromise in Agonistic Deliberation}

If consensus is neither a probable nor a desirable outcome of a dialogue between a company and an NGO, what outcome could fit with agonistic deliberation? We think that compromise is also a viable outcome of dialogue and that many collaborations between companies and NGOs, in fact, are based on compromises. Warren and Mansbridge $(2013,97)$ define a compromise as "an agreement in which all sides sacrifice something of value (i.e., make concessions) to improve on the status quo from the perspective of each." When an agreement is characterized as compromise, both parties in the agreement can retain their independence and can also maintain a critical distance from the views of the other. For NGOs that want to maintain such critical distance from companies, aiming at a workable compromise in dialogue and collaboration fits better to their role as challenger and social critic. 
Many authors indicate that collaboration between companies and NGOs requires that participants reach agreement on the division of responsibilities (e.g., Van Tulder et al. 2016; Roloff 2008; Rondinelli and London 2003). In our view, such an agreement is more likely to be a compromise rather than a consensus. Seitanidi and Crane $(2009,422)$, for example, mention explicitly that partners in a collaboration can overcome crises "by not avoiding conflict but rather accept disagreements as functional which permits retaining the organisation's identity intact." We, therefore, think that agonistic deliberation could better explain what is going on in actual dialogues and collaborations between companies and NGOs compared to a view based on pure communicative action. The necessary element of cooperation is that both parties are willing to accept the terms of collaboration and are willing to carry out their tasks, even though they might have different reasons for doing so. If the interests in and commitment to cooperation are strong enough, it would not require a complete convergence of views on the matter.

In general, it is more likely that NGOs that adopt a reformative stance are willing to engage in dialogue with companies about their social responsibility compared to radical NGOs. Yet even when a moderate NGO enters a dialogue with a company in order to cooperate on behalf of a societal issue, they will-in most cases, and to a certain degree - have to make concessions for the sake of pragmatic improvement. Although it may sound contradictory, one could even make the argument that radical NGOs consider consensus as more important compared to reformative ones. As Mena and Waeger argue, "radicals only evaluate proactive firms positively if they address CR [corporate responsibility] issues in ways radicals consider entirely satisfactory" (Mena and Waeger 2014, 1096). In other words, radical groups will approach companies positively and constructively only if there is a possibility of convergence in views - a consensus. However, since they do not believe in such a possibility (or only in some exceptional cases), they do not engage in a consensual dialogue or consider cooperating with companies. "In contrast, reformative activist groups emphasize the importance of achieving workable solutions ... even if they do not immediately address CR issues comprehensively" (Mena and Waeger 2014, 1096). Hence, while reformative groups recognize that they would not easily achieve consensus with companies, they do not take this as a reason not to engage in dialogue with them, because they consider a compromise as sufficient ground for dialogue and cooperation.

\section{The Deliberative Aspect of Agonistic Deliberation}

We have argued for the legitimacy of conflict and self-interest in deliberation. However, as Hirschman has noted, conflict can function both as glue and as solvent: it can be something that binds us together, but also something that tears us apart (Hirschman 1994). In order to avoid a situation in which conflict within stakeholder dialogue becomes a solvent, certain deliberative norms need to be respected. The same holds in relation to self-interest: its presence can only be legitimized within deliberative boundaries. By employing the distinction between antagonists and adversaries, we already presupposed certain deliberative norms. 
Unlike antagonists, adversaries recognize the legitimacy of their opponents, even though they pursue different ends (Mouffe 2005, 2000a). This recognition of the other as having the right to have a different view is necessary to make the management of dissensus possible. Hence, the interaction between adversaries is guided by certain mutually accepted rules, such as abstaining from violent behavior. As soon as one starts to use violence against one's opponent, that turns him into an antagonist. ${ }^{12}$

Beyond recognizing the legitimacy of one's opponent, our definition of agonistic deliberation states that participants should be willing to mutually justify and accommodate their views. Hence, mutual justification and accommodation is the central deliberative norm that should guide agonistic deliberation. It implies that participants in a dialogue, even though they are in conflict without a prospect of resolution, should be willing to give and respond to reasons. It also implies that participants should be willing to explore differences and agreements (without saying that they should reach agreement). The exploration of differences can lead to better mutual understanding, so that participants know from each other where they disagree and why. This principle is very much in line with recent work in deliberative democracy. For example, Thompson (2008, 504) notes that mutual justification is "the most important distinguishing characteristic of deliberation." This norm is not the same as aiming at consensus. Mutual justification is very well possible without consensus as aim or as outcome. A dialogue based on this norm might also result in a mutual clarification of positions, in increased mutual understanding, or in one or more of the participants changing his or her mind. Rescher explains the difference between mutual justification and the mere aim to reach agreement:

When I realize that my position on some issue of consequence disagrees with yours, I am well advised to inquire into how it is that you have rendered a conclusion different from mine-and presumably then to change my view if the grounds for yours appear to be stronger. But I am not well advised to worry about the bare fact that your beliefs differ from mine in ways that are detached from the issues that relate to grounds and reasons. It makes good sense to revise beliefs to accommodate them to other evidence, but it makes no rational sense to revise them to accommodate other people (Rescher 1993, 17, emphasis in original).

What Rescher makes clear is that consensus should not be a goal in itself, in order to conform to the beliefs of others. Of course, defenders of a consensus orientation such as Habermas do not argue that agreement should be reached "in ways that are detached from the issues that relate to grounds and reasons." On the contrary,

\footnotetext{
${ }^{12}$ We recognize the difficulty of how to define violence. Campaigns of NGOs can seriously damage companies (for example, successful appeals to consumers to boycott a company or product), although we would not immediately classify every campaign that results in damage as violence. See also Baur and Palazzo $(2011,590-91)$ on the criterion of 'civil behavior' for the legitimacy of NGOs. For a general and very informative study about the ethics of adversarial relations in public and professional life, see Applbaum (1999).
} 
they insist that a consensus is only valuable if it is reasonable or rationally motivated (e.g., Habermas 1996). At the same time, Habermas and others insist on the importance of the connection between reasonableness and an orientation towards consensus. We hold that this connection does not have to be strong. What is important is that participants within a dialogue are willing to make themselves intelligible, to give an account of their views and beliefs. In order for a dialogue to count as reasonable in this sense, an orientation towards consensus is not necessary. ${ }^{13}$

There is one significant complication in relation to the willingness to reconsider one's own view: most often, stakeholders within a dialogue do not participate on their own behalf, but represent a group or an organization. That means that, as part of their role, they have a responsibility to represent a specific view within a dialogue. They cannot simply change their mind during the dialogue if they become convinced of some alternative view, because they have to give an account of their input to the group or organization they represent. Moreover, they could only change their view if they have a mandate to do so, or after a round of feedback within their own group or organization. Stakeholder representatives play, so to say, a 'two-level game,' both within their group or organization and within the dialogue (cf. Warren and Mansbridge 2013, 96). Although this complicates the matters, it would be even more complicating for a consensus-oriented dialogue. In that case, a dialogue between actors, who-as part of their role-have no room to change their position, does not seem to make sense. Since agonistic deliberation allows for different outcomes, it can also better account for this complication. For example, a compromise allows for agreement on concrete goals or actions, while at the same time leaving room to maintain one's originals views and ideals.

\section{The Scope of Agonistic Deliberation}

Until now, we have argued rather broadly that companies and NGOs engaging in dialogue about societal issues should not avoid conflict and should incorporate issues of self-interest. At the same time, we have left open the possibility that a consensus orientation can also be fruitful and appropriate in certain cases. However, we have not specified under which conditions the participants in a dialogue should resort to communicative action or to agonistic deliberation. Although it is beyond the scope of this article to elaborate extensively on this question, we want to give some remarks on the conditions when agonistic deliberation applies.

First, as we have argued before, agonistic deliberation is most suitable in cases when the core activities of companies are in conflict with the societal values that

\footnotetext{
${ }^{13}$ Of course, it is very difficult to have such a reasonable attitude if you know or suspect that others will not be listening nor willing to be reasonable either. These requirements only 'work' when all participants of a dialogue commit themselves to them, and when there is the trust among every participant that others have the same attitude. When stakeholder dialogue entirely lacks any of these deliberative elements, the interaction will be purely based on strategic action. This would be problematic, not because the pursuit of private interests is as such problematic, but because a conflict about ethical and societal issues should not be reduced to a conflict between private interests (cf. Benjamin 1990, 15-20).
} 
NGOs defend. Especially in those cases, NGOs play an important role in voicing social criticism, mobilizing the public, and stimulating social change. Although we have argued that it is still valuable that NGOs and companies engage in dialogue in such cases, a consensus orientation is not necessary and might even undermine the critical role of NGOs.

Second, agonistic deliberation will be more appropriate in cases of power differences between companies and NGOs (cf. Dawkins 2015). The bigger the power differences are, the more difficult it will be to reach a genuine and unforced consensus. In such cases, it will be better to allow for more conflict and to acknowledge differences, so that actors with less power are also able to articulate their positions. Furthermore, in cases where there are big power differences, it is likely that the interests of minority groups are not taken into account (cf. Sanders 1997). For that reason, agonistic deliberation might be desirable, because it aims to give room for the articulation of self-interest.

Third, agonistic deliberation does not have to apply to all the aspects of a dialogue about a societal issue. For example, it could be that participants can quite easily agree on the causes of a problem, but not on who is responsible for the solution. Agonistic deliberation is better suited for the latter, while communicative action might be appropriate to discuss the former. We can expect that the biggest conflicts between companies and NGOs will be about the division of responsibilities for addressing a social problem, which are conflicts that relate to action. It is our intuition that agonistic deliberation is most appropriate to discuss issues of action: what has to be done and who has to do what.

Fourth, when the debated topics are highly contested, and the differences in views between actors are large, agonistic deliberation can also be more suitable. This contrasts the claim made by Patzer et al. $(2018,341)$, who argue that "the newer the issue, the greater the disagreements about it, the likelier the conflicts between different stakeholder interests, and the greater the range of values it concerns . . . the more it will require communicative action" instead of strategic action. Probably the authors are right to prefer communicative action over pure strategic action in such cases, because the latter will come down to a mere power struggle. However, our argument would be that a form of communication that leaves more room for conflict, self-interest, and persistent differences than communicative action would be both more realistic and more desirable in the case of contested issues.

Fifth and last, it might be asked whether agonistic deliberation applies in different institutional contexts. For example, it has been argued within political CSR that deliberation between companies and societal actors becomes more important under conditions of globalization or when nation states are weak (Scherer and Palazzo 2007, 2011; Scherer et al. 2016; Patzer, Voegtlin, and Scherer 2018). Does the same hold for agonistic deliberation? The short answer is that agonistic deliberation does (of course) not equally apply in all institutional contexts. The long answer we have to suspend. Our approach is restricted to the question: Given that companies and NGOs engage in dialogue about societal issues, what kind of communicative norms should or should not be adopted by them? Specifying the 
institutional contexts in which agonistic deliberation is more or less needed is beyond the scope of this article.

\section{CONCLUSION}

In this article, we have been discussing the question of what a suitable regulative ideal is for stakeholder dialogue in the case of companies and NGOs. Our point has been that, when companies and NGOs engage in dialogue about a societal issue, it will often be better to allow for conflict and to incorporate strategic considerations, instead of striving for consensus. Agonistic deliberation is a conceptualization of an alternative to communicative action, one we think of as more realistic and more adapted to the context in which companies and NGOs operate. Our main arguments are that an orientation towards consensus is in tension with the function of NGOs to voice social criticism, and that the expectation to set aside strategic considerations is in tension with the idea of a competitive market in which companies are allowed to exhibit a certain partiality towards their own (commercial) interests. At the same time, agonistic deliberation upholds the importance of mutual justification, which requires that participants in a dialogue are willing to give a reasonable account of their position.

Our approach to stakeholder dialogue provides a third option between the ideal of communicative action on the one hand, and a purely conflictual or strategic understanding of the interaction between companies and NGOs on the other hand. Conflict and self-interest will always be present in stakeholder dialogues, and both can have a legitimate and constructive role. By taking this into account, agonistic deliberation has the potential to change the way in which stakeholder dialogue is understood and performed in practice.

\section{ACKNOWLEDGEMENTS}

We thank The Netherlands Organization for Scientific Research (NWO, grant number 313-99-302) and the Dutch Choices Foundation (stichting Ik Kies Bewust) for funding this research. We also thank Business Ethics Quarterly associate editor Guido Palazzo and three anonymous reviewers for the time and effort they have put into reviewing this article.

\section{REFERENCES}

Applbaum, Arthur Isak. 1999. Ethics for Adversaries: The Morality of Roles in Public and Professional Life. Princeton, NJ: Princeton University Press.

Arenas, Daniel, Josep M. Lozano, and Laura Albareda. 2009. "The Role of NGOs in CSR: Mutual Perceptions Among Stakeholders.” Journal of Business Ethics 88 (1): 175-97.

Baur, Dorothea, and Guido Palazzo. 2011. "The Moral Legitimacy of NGOs as Partners of Corporations.” Business Ethics Quarterly 21 (04): 579-604.

Baur, Dorothea, and Hans Peter Schmitz. 2012. "Corporations and NGOs: When Accountability Leads to Co-Optation." Journal of Business Ethics 106 (1): 9-21.

Bendell, Jem. 2003. "Talking for Change? Reflections on Effective Stakeholder Dialogue." In Unfolding Stakeholder Thinking 2: Relationships, Communication, Reporting 
and Performance, edited by Jörg Andriof, Sandra Waddock, Brian Husted, and

Sandra Sutherland Rahman, 53-69. Sheffield, UK: Greenleaf.

Benjamin, Martin. 1990. Splitting the Difference: Compromise and Integrity in Ethics and Politics. Lawrence, KS: University of Kansas Press.

Berman, Shawn L., Andrew C. Wicks, Suresh Kotha, and Thomas M. Jones. 1999. "Does Stakeholder Orientation Matter? The Relationship Between Stakeholder Management Models and Firm Financial Performance." Academy of Management Journal 42 (5): 488-506.

Blok, Vincent. 2014a. "The Metaphysics of Collaboration: Identity, Unity and Difference in Cross-sector Partnerships for Sustainable Development:" Philosophy of Management 13 (2): 53-74.

Blok, Vincent. 2014b. "Look Who's Talking: Responsible Innovation, the Paradox of Dialogue and the Voice of the Other in Communication and Negotiation Processes." Journal of Responsible Innovation 1 (2): 171-90.

Blok, Vincent. 2019. "From Participation to Interruption: Toward an Ethics of Stakeholder Engagement, Participation and Partnership in Corporate Social Responsibility and Responsible Innovation.” In International Handbook of Responsible Innovation: A Global Resource, edited by René von Schomberg and Jonathan Hankins, 243-258. Cheltenham, UK: Edward Elgar.

Brown, Judy, and Jesse Dillard. 2013. "Critical Accounting and Communicative Action: On the Limits of Consensual Deliberation." Critical Perspectives on Accounting 24 (3): 176-90.

Burchell, Jon, and Joanne Cook. 2006. "Assessing the Impact of Stakeholder Dialogue: Changing Relationships between NGOs and Companies." Journal of Public Affairs 6 (3-4): 210-27.

Burchell, Jon, and Joanne Cook. 2013a. "Sleeping with the Enemy? Strategic Transformations in Business-NGO Relationships Through Stakeholder Dialogue." Journal of Business Ethics 113 (3): 505-18.

Burchell, Jon, and Joanne Cook. 2013b. "CSR, Co-Optation and Resistance: The Emergence of New Agonistic Relations Between Business and Civil Society." Journal of Business Ethics 115 (4): 741-54.

Choi, Jaepil, and Heli Wang. 2009. "Stakeholder Relations and the Persistence of Corporate Financial Performance." Strategic Management Journal 30 (8): 895-907.

Crane, Andrew, and Sharon Livesey. 2003. "Are You Talking to Me? Stakeholder Communication and the Risks and Rewards of Dialogue." In Unfolding Stakeholder Thinking 2: Relationships, Communication, Reporting and Performance, edited by Jörg Andriof, Sandra Waddock, Brian Husted, and Sandra Sutherland Rahman, 39-52. Sheffield, UK: Greenleaf.

Crouch, Colin. 2011. The Strange Non-Death of Neoliberalism. Cambridge, UK: Polity Press.

Dawkins, Cedric. 2015. "Agonistic Pluralism and Stakeholder Engagement." Business Ethics Quarterly 25 (1): 1-28.

Dubbink, Wim. 2004. "The Fragile Structure of Free-Market Society: The Radical Implications of Corporate Social Responsibility." Business Ethics Quarterly 14 (1): 23-46.

Elster, Jon. 2000. “Arguing and Bargaining in Two Constituent Assemblies.” Journal of Constitutional Law 2 (2): 345-421.

Erman, Eva. 2009. "What Is Wrong with Agonistic Pluralism?: Reflections on Conflict in Democratic Theory." Philosophy \& Social Criticism 35 (9): 1039-62. 
Foster, David, and Jan Jonker. 2005. "Stakeholder Relationships: The Dialogue of Engagement." Corporate Governance: The International Journal of Business in Society 5 (5): 51-7.

Freeman, R. Edward, Jeffrey S. Harrison, Andrew C. Wicks, Bidhan Parmar, and Simone de Colle. 2010. Stakeholder Theory: The State of the Art. Cambridge, UK: Cambridge University Press.

García-Marzá, Domingo. 2005. "Trust and Dialogue: Theoretical Approaches to Ethics Auditing.” Journal of Business Ethics 57 (3): 209-19.

Gilbert, Dirk Ulrich, and Andreas Rasche. 2007. "Discourse Ethics and Social Accountability: The Ethics of SA 8000.” Business Ethics Quarterly 17 (02): 187-216.

Golob, Ursa, and Klement Podnar. 2014. "Critical Points of CSR-Related Stakeholder Dialogue in Practice.” Business Ethics: A European Review 23 (3): 248-57.

Habermas, Jürgen. 1985. The Theory of Communicative Action, Volume 1: Reason and the Rationalization of Society. Translated by Thomas MacCarthy. Boston: Beacon Press.

Habermas, Jürgen. 1987. The Theory of Communicative Action, Volume 2: Lifeworld and System: A Critique of Functionalist Reason. Translated by Thomas MacCarthy. Boston: Beacon Press.

Habermas, Jürgen. 1990. Moral Consciousness and Communicative Action. Studies in Contemporary German Social Thought. Cambridge, MA: MIT Press.

Habermas, Jürgen. 1996. Between Facts and Norms: Contributions to a Discourse Theory of Law and Democracy. From Studies in Contemporary German Social Thought. Cambridge, MA: MIT Press.

Habermas, Jürgen. 1998. “Three Normative Models of Democracy.” In The Inclusion of the Other: Studies in Political Theory, reprint, 239-52. Cambridge, UK: Polity Press.

Heath, Joseph. 2007. "An Adversarial Ethic for Business: Or When Sun-Tzu Met the Stakeholder." Journal of Business Ethics 72 (4): 359-74.

Heath, Joseph. 2014. Morality, Competition, and the Firm: The Market Failures Approach to Business Ethics. New York: Oxford University Press.

Heath, Joseph. 2019. “The Moral Status of Profit." In The Oxford Handbook of Ethics and Economics, edited by Mark D. White, 337-357. Oxford: Oxford University Press.

Hirschman, Albert O. 1970. Exit, Voice, and Loyalty: Responses to Decline in Firms, Organizations, and States. Cambridge, MA: Harvard University Press.

Hirschman, Albert O. 1994. "Social Conflicts as Pillars of Democratic Market Society." Political Theory 22 (2): 203-18.

Hond, Frank den, and Frank de Bakker. 2007. "Ideologically Motivated Activism: How Activist Groups Influence Corporate Social Change Activities." Academy of Management Review 32 (3): 901-24.

Høvring, Christiane Marie, Sophie Esmann Andersen, and Anne Ellerup Nielsen. 2018. "Discursive Tensions in CSR Multi-Stakeholder Dialogue: A Foucauldian Perspective." Journal of Business Ethics 152 (3): 627-45.

Hussain, Waheed, and Jeffrey Moriarty. 2016. "Accountable to Whom? Rethinking the Role of Corporations in Political CSR.” Journal of Business Ethics 149 (3): 519-34.

Iivonen, Kirsti. 2018. "Defensive Responses to Strategic Sustainability Paradoxes: Have Your Coke and Drink It Too!" Journal of Business Ethics 148 (2): 309-27.

Johnson, J. 1991. "Habermas on Strategic and Communicative Action." Political Theory 19 (2): 181-201. 
Johnson-Cramer, Michael E., Shawn L. Berman, and James E. Post. 2003. "Re-Examining the Concept of 'Stakeholder Management." In Unfolding Stakeholder Thinking 2: Relationships, Communication, Reporting and Performance, edited by Jörg Andriof, Sandra Waddock, Brian Husted, and Sandra Sutherland Rahman, 145-61. Sheffield, UK: Greenleaf.

Jones, Thomas M. 1995. "Instrumental Stakeholder Theory: A Synthesis of Ethics and Economics." Academy of Management Review 20 (2): 404-37.

Kaptein, Muel, and Rob Van Tulder. 2003. "Toward Effective Stakeholder Dialogue." Business and Society Review 108 (2): 203-24.

Kerkhof, Marleen van de. 2006. "Making a Difference: On the Constraints of Consensus Building and the Relevance of Deliberation in Stakeholder Dialogues." Policy Sciences 39 (3): 279-99.

Knops, Andrew. 2007. "Debate: Agonism as Deliberation? On Mouffe's Theory of Democracy." Journal of Political Philosophy 15 (1): 115-26.

Mansbridge, Jane. 2006. "Conflict and Self-Interest in Deliberation.” In Deliberative Democracy and Its Discontents, edited by Semantha Besson and José Luis Martí, 107-32. Farnham, UK: Ashgate Publishing Group.

Mansbridge, Jane. 2009. "Deliberative and Non-Deliberative Negotiations." Harvard Kennedy School, Working Paper RWP09-010. https://dash.harvard.edu/handle/ $1 / 4415943$.

Mansbridge, Jane, James Bohman, Simone Chambers, David Estlund, Andreas Føllesdal, Archon Fung, Cristina Lafont, Bernard Manin, and José Luis Martí. 2010. "The Place of Self-Interest and the Role of Power in Deliberative Democracy." Journal of Political Philosophy 18 (1): 64-100.

Markell, Patchen. 1997. "Contesting Consensus: Rereading Habermas on the Public Sphere." Constellations 3 (3): 377-400.

Martens, Kerstin. 2002. "Mission Impossible? Defining Nongovernmental Organizations." Voluntas: International Journal of Voluntary and Nonprofit Organizations 13 (3): 271-85.

Mena, Sébastien, and Guido Palazzo. 2012. "Input and Output Legitimacy of MultiStakeholder Initiatives.” Business Ethics Quarterly 22 (03): 527-56.

Mena, Sébastien, and Daniel Waeger. 2014. "Activism for Corporate Responsibility: Conceptualizing Private Regulation Opportunity Structures: Private Regulation Opportunity Structures." Journal of Management Studies 51 (7): 1091-117.

Moog, Sandra, André Spicer, and Steffen Böhm. 2015. "The Politics of Multi-Stakeholder Initiatives: The Crisis of the Forest Stewardship Council." Journal of Business Ethics 128 (3): 469-93.

Mouffe, Chantal. 1999. “Deliberative Democracy or Agonistic Pluralism?” Social Research 66 (3): 745-58.

Mouffe, Chantal. 2000a. The Democratic Paradox. London ; New York: Verso.

Mouffe, Chantal. 2000b. "Deliberative Democracy or Agonistic Pluralism." IHS Political Science Series, no. 72. http://irihs.ihs.ac.at/1312/.

Mouffe, Chantal. 2005. On the Political (Thinking in Action). New York: Routledge.

Noland, James, and Robert A. Phillips. 2010. "Stakeholder Engagement, Discourse Ethics and Strategic Management." International Journal of Management Reviews 12 (1): 39-49.

Norman, Wayne. 2011. "Business Ethics as Self-Regulation: Why Principles That Ground Regulations Should Be Used to Ground Beyond-Compliance Norms as Well." Journal of Business Ethics 102 (S1): 43-57. 
Palazzo, Guido, and Andreas Georg Scherer. 2006. "Corporate Legitimacy as Deliberation: A Communicative Framework." Journal of Business Ethics 66 (1): 71-88.

Patzer, Moritz, Christian Voegtlin, and Andreas Georg Scherer. 2018. "The Normative Justification of Integrative Stakeholder Engagement: A Habermasian View on Responsible Leadership." Business Ethics Quarterly 28 (3): 325-54.

Payne, Stephen L., and Jerry M. Calton. 2002. "Towards a Managerial Practice of Stakeholder Engagement.” Journal of Corporate Citizenship 2002 (6): 37-52.

Phillips, Robert A. 1997. "Stakeholder Theory and A Principle of Fairness." Business Ethics Quarterly 7 (1): 51-66.

Rasche, Andreas, and Daniel E. Esser. 2006. "From Stakeholder Management to Stakeholder Accountability: Applying Habermasian Discourse Ethics to Accountability Research.” Journal of Business Ethics 65 (3): 251-67.

Rawls, John. 1987. "The Idea Of An Overlapping Consensus." Oxford Journal of Legal Studies 7 (1): 1-25.

Rescher, Nicholas. 1993. Pluralism: Against the Demand for Consensus. New York: Oxford University Press.

Reynolds, MaryAnn, and Kristi Yuthas. 2008. "Moral Discourse and Corporate Social Responsibility Reporting.” Journal of Business Ethics 78 (1-2): 47-64.

Roloff, Julia. 2008. "Learning from Multi-Stakeholder Networks: Issue-Focussed Stakeholder Management." Journal of Business Ethics 82 (1): 233-50.

Rondinelli, Dennis A., and Ted London. 2003. "How Corporations and Environmental Groups Cooperate: Assessing Cross-Sector Alliances and Collaborations." Academy of Management Perspectives 17 (1): 61-76.

Rummens, Stefan. 2009. "Democracy as a Non-Hegemonic Struggle? Disambiguating Chantal Mouffe's Agonistic Model of Politics.” Constellations 16 (3): 377-91.

Sabadoz, Cameron, and Abraham Singer. 2017. "Talk Ain't Cheap: Political CSR and the Challenges of Corporate Deliberation." Business Ethics Quarterly 27 (02): 183-211.

Sanders, Lynn M. 1997. “Against Deliberation.” Political Theory 25 (3): 347-76.

Scherer, Andreas Georg, and Guido Palazzo. 2007. "Toward a Political Conception of Corporate Responsibility: Business and Society Seen from a Habermasian Perspective." Academy of Management Review 32 (4): 1096-120.

Scherer, Andreas Georg, and Guido Palazzo. 2011. "The New Political Role of Business in a Globalized World: A Review of a New Perspective on CSR and Its Implications for the Firm, Governance, and Democracy." Journal of Management Studies 48 (4): 899-931.

Scherer, Andreas Georg, Andreas Rasche, Guido Palazzo, and André Spicer. 2016. "Managing for Political Corporate Social Responsibility: New Challenges and Directions for PCSR 2.0." Journal of Management Studies 53 (3): 273-98.

Seitanidi, Maria May, and Andrew Crane. 2009. "Implementing CSR Through Partnerships: Understanding the Selection, Design and Institutionalisation of Nonprofit-Business Partnerships." Journal of Business Ethics 85 (S2): 413-29.

Selsky, J. W., and Barbara Parker. 2005. "Cross-Sector Partnerships to Address Social Issues: Challenges to Theory and Practice." Journal of Management 31 (6): 849-73.

Thompson, Dennis F. 2008. "Deliberative Democratic Theory and Empirical Political Science." Annual Review of Political Science 11 (1): 497-520.

Trumpy, Alexa J. 2008. "Subject to Negotiation: The Mechanisms Behind Co-Optation and Corporate Reform.” Social Problems 55 (4): 480-500. 
Unerman, Jeffrey, and Mark Bennett. 2004. "Increased Stakeholder Dialogue and the Internet: Towards Greater Corporate Accountability or Reinforcing Capitalist Hegemony?" Accounting, Organizations and Society 29 (7): 685-707.

van Huijstee, Mariëtte, and Pieter Glasbergen. 2008. "The Practice of Stakeholder Dialogue between Multinationals and NGOs." Corporate Social Responsibility and Environmental Management 15 (5): 298-310.

Van Tulder, Rob, Maria May Seitanidi, Andrew Crane, and Stephen Brammer. 2016. "Enhancing the Impact of Cross-Sector Partnerships: Four Impact Loops for Channeling Partnership Studies.” Journal of Business Ethics 135 (1): 1-17.

Warren, Mark E., and Jane Mansbridge. 2013. "Deliberative Negotiation.” In Negotiating Agreement in Politics, 86-120. Washington, D.C.: American Political Science Association.

Yaziji, Michael, and Jonathan Doh. 2009. NGOs and Corporations: Conflict and Collaboration. Cambridge, UK: Cambridge University Press.

Zakhem, Abe. 2008. "Stakeholder Management Capability: A Discourse-Theoretical Approach." Journal of Business Ethics 79 (4): 395-405.

Teunis BRAND studied economics (Erasmus University Rotterdam) and philosophy (Free University Amsterdam). Since 2015 he is working on a PhD project about responsible innovation in the food industry. His focus is on stakeholder engagement and dialogue. One of the central aims of his research is to analyze the tensions that (might) occur when companies engage in dialogue with societal stakeholders about social issues like public health. Another question his research addresses is the nature of good stakeholder dialogue, and what kind of norms participants should adhere to.

VINCENT BLOK is associate professor at the Business Management and Organisation Group and the Philosophy Group at Wageningen University (The Netherlands). In 2005 he received his $\mathrm{PhD}$ in philosophy at Leiden University with a specialization in philosophy of technology. Together with a research group of three postdocs and six PhD students, Blok is involved in several (European) research projects at the crossroads of business ethics, philosophy of technology, and responsible innovation. His books include Ernst Jünger's Philosophy of Technology: Heidegger and the Poetics of the Anthropocene (Routledge, 2017). Blok's work has appeared in, amongst others, the Journal of Business Ethics, Business \& Society, Environmental Values and Business Ethics: A European Review.

MARCEL VerweiJ holds the chair of philosophy at Wageningen University (The Netherlands). Before Verweij came to Wageningen, he worked as a philosopher and ethicist at Utrecht University, the University of Amsterdam, and the University Medical Centre Nijmegen, and as visiting scholar at the universities of Stellenbosch, Keele, and the London School of Hygiene and Tropical Medicine. His research and teaching cover a very broad area in applied philosophy and ethics, including animal ethics and business ethics, but his primary focus is public health. Together with Angus Dawson (University of Sydney) he initiated public health ethics as a new area of study in moral philosophy. They are founding editors in chief of Public Health Ethics, a journal published by Oxford University Press. This journal is now the centre of a flourishing interdisciplinary scientific field. 